\title{
Is There a Gender Difference of Metabolic Syndrome in Hemodialysis?
}

\author{
Imen Gorsane, Madiha Mahfoudhi*, Mounira El Euch, Fathi Younsi, Taieb Ben Abdallah \\ Internal Medicine A Department, Charles Nicolle Hospital, Tunis, Tunisia \\ Email: ${ }^{*}$ madiha mahfoudhi@yahoo.fr
}

Received 20 May 2015; accepted 10 October 2015; published 13 October 2015

Copyright (C) 2015 by authors and Scientific Research Publishing Inc.

This work is licensed under the Creative Commons Attribution International License (CC BY). http://creativecommons.org/licenses/by/4.0/

c) (i) Open Access

\begin{abstract}
The prevalence of metabolic syndrome is high in hemodialysis. MS is defined by the combination of high blood pressure, dyslipidemia, central obesity and a state of insulin resistance. The aim of this work is to see if there's a difference by gender in the different parameters of metabolic syndrome and in cardiovascular morbidity in our hemodialysis patients. It is a cross-sectional study of 120 patients older than 18 years on hemodialysis. The metabolic syndrome was defined according to the criteria of the National Cholesterol Education Program Adult Treatment Panel III (NCEP ATP III). A comparison by gender was performed for the following parameters: age, diabetes, hypertension, obesity, dyslipidemia, coronary artery disease and heart failure. Forty chronic hemodialysis patients with metabolic syndrome have been the subject of this study. The sex ratio was 1.88 and the mean age was 55.97 years. Seventy percent had diabetes and $90 \%$ were hypertensive. Coronary artery disease was present in $57.5 \%$ of cases and heart failure in $52.5 \%$ of cases. The study by gender showed no significant difference except for the prevalence of hyper LDL cholesterol. There is a high prevalence of cardiovascular complications in men but a significant difference by gender could not be demonstrated.
\end{abstract}

\section{Keywords}

Metabolic Syndrome, Gender, Renal Dialysis, Cardiovascular Events

\section{Introduction}

Metabolic syndrome (MS) is defined by the combination of hypertension, dyslipidemia, central obesity and a state of insulin resistance [1]. Patients on renal replacement therapy have a high prevalence of MS [2], up to $70 \%$ of cases in some studies [3].

${ }^{*}$ Corresponding author.

How to cite this paper: Gorsane, I., Mahfoudhi, M., El Euch, M., Younsi, F. and Abdallah, T.B. (2015) Is There a Gender Difference of Metabolic Syndrome in Hemodialysis? International Journal of Clinical Medicine, 6, 711-715.

http://dx.doi.org/10.4236/ijcm.2015.610094 
MS includes several metabolic abnormalities; each one predisposes to cardiovascular risk. It is associated with higher morbidity and mortality in the general population. However, the effects of MS on hemodialysis patients, who are at high cardiovascular risk, have not been clearly defined.

It is known that female patients are at low cardiovascular risk, at least until 60 years, in the general population.

We propose in this study to see the impact of MS on morbidity and mortality in hemodialysis patients and to study a possible difference by gender in this group.

\section{Patients and Methods}

It is a cross-sectional study of 120 hemodialysis patients in the Hemodialysis Unit of the Nephrology Department of Medicine A at the Charles Nicolle Hospital in Tunis in January 2015.

Inclusion criteria: Chronic hemodialysis patients with MS defined according to National Cholesterol Education Program Adult Treatment Panel III (NCEP ATP III) [4], by the presence of 3 or more of these 5 criteria:

1) Central obesity: waist circumference $\geq 102 \mathrm{~cm}$ (male), $\geq 88 \mathrm{~cm}$ (female).

2) Dyslipidemia: TG $\geq 1.7 \mathrm{mmol} / \mathrm{l}(150 \mathrm{mg} / \mathrm{dl})$.

3) Dyslipidemia: HDL-C $<40 \mathrm{mg} / \mathrm{dl}$ (male), $<50 \mathrm{mg} / \mathrm{dl}$ (female).

4) Blood pressure $\geq 130 / 85 \mathrm{mmHg}$ (or treated for hypertension).

5) Fasting plasma glucose $\geq 6.1 \mathrm{mmol} / \mathrm{l}(110 \mathrm{mg} / \mathrm{dl})$.

Exclusion criteria: Patients on hemodialysis for less than 3 months and patients with acute infection, or active neoplasia.

Forty hemodialysis patients with MS were selected for this study. For each patient were collected from medical records, epidemiological, anthropometric, clinical, biological and radiological data. A comparison by gender was conducted for the following parameters: age, diabetes, high blood pressure, obesity, triglycerides, HDL cholesterol, LDL cholesterol, the prevalence of coronary artery disease and heart failure.

\section{Statistical Study:}

Categorical variables were summarized by their relative frequencies, quantitative variables were summarized by their mean.

The software used is the BiostaTGV online.

A study of the correlation was made between the different parameters by the statistical test CHI2.

$\mathrm{p}$ value $\leq 0.05$ was regarded as significant.

\section{Results}

Forty patients were analyzed. They were 23 men (57.5\%) and 17 women (42.5\%) with a sex ratio of 1.88 . The average age was 55.97 years (23 - 78 years). The average age for men was 56.17 years; for women, it was 55.7 years. The age difference was not statistically significant $(\mathrm{p}=0.9)$.

The prevalence of smoking was $55 \%$. A reduced physical activity was observed in $75 \%$ of patients. The average age of discovery of renal failure was 47.82 years (18 - 66 years).

There was no correlation between age and hemodialysis $(\mathrm{p}=0.5)$.

Seventeen patients had vascular nephropathy, 12 had diabetic nephropathy, 8 had chronic glomerular nephritis, 2 had chronic interstitial nephropathy and one patient had hereditary kidney disease (tuberous sclerosis of Bourneville). The average time between discovery of kidney failure and the onset of hemodialysis was 20 months.

The average of hemodialysis was 79 months (5 - 370 months). The average KT/V was 1.88 .

Eighteen patients (45\%) had hyperuricemia with an average of serum uric acid of $407.55 \mathrm{mmol} / \mathrm{l}, 31$ patients (77.5\%) had a good nutritional status with serum albumin $\geq 30 \mathrm{~g} / \mathrm{l}$. Twenty six patients (65\%) had an inflammatory syndrome. Secondary hyperparathyroidism was found in 23 patients (57.5\%) with a mean PTH of 405.6 $\mathrm{pg} / \mathrm{ml}$.

Seventy percent of patients had diabetes: 18 (78.26\%) men and 10 (58.82\%) women. This difference was not statistically significant $(\mathrm{p}=0.18)$.

The mean fasting blood glucose was $7.29 \mathrm{mmol} / \mathrm{l}$. The average $\mathrm{Hb}$ A1C was $8.25 \%$. The prevalence of hypertension was 90\%: 22 men (61.11\%) and 14 women (38.89\%). This difference was not statistically significant (p $=0.16)$. 
The overall prevalence of abdominal obesity was $67.5 \%$. Abdominal obesity was found in $48.14 \%$ of women and $51.85 \%$ of men. This difference was not statistically significant $(\mathrm{p}=0.18)$. Hypertriglyceridemia was found in $77.5 \%$ of patients: five (88.23\%) women and 16 (69.56\%) men. There was no statistical difference between the mean values of triglycerides analyzed by gender: $2.57 \mathrm{mmol} / \mathrm{l}$ in women and $3.82 \mathrm{mmol} / \mathrm{l}$ in men $(\mathrm{p}=0.1)$.

The hypo-HDL cholesterol was found in $97.5 \%$ of patients: $0.74 \mathrm{mmol} / \mathrm{l}$ in women and $0.69 \mathrm{mmol} / \mathrm{l}$ in men. However, this difference was not significant $(\mathrm{p}=0.37)$.

The hyper-LDL cholesterol was found in 14 patients (35\%). The average LDL cholesterol of women was 3.84 $\mathrm{mmol} / \mathrm{l}$, the average LDL cholesterol of men was $2.66 \mathrm{mmol} / \mathrm{l}$. This difference was statistically significant $(\mathrm{p}=$ 0.003).

Twenty nine patients (72.5\% of cases), had accomplished criteria of metabolic syndrome.

The prevalence of coronary artery disease was 57.5\% (23 patients): Nine women (52.9\%) and 14 men (60.9\%). This difference was not statistically significant $(\mathrm{p}=0.16)$. Eight patients $(20 \%)$ developed myocardial infarction. The prevalence of heart failure was 52.5\% (21 patients): 8 women (47.1\%) and 13 men (56.5\%). This difference was not statistically significant $(\mathrm{p}=0.74)$.

The study by gender is showed in Table 1.

\section{Discussion}

MS has a high prevalence in hemodialysis' patients and is a risk factor for cardiovascular disease. It is also the leading cause of mortality in chronic kidney disease [2].

The most prominent component of the MS is hypertension, present in $85 \%$ of cases, followed by diabetes, present in $46 \%$ of cases [5] [6]. In our study, the hypertension and the diabetes were present in $90 \%$ of cases and in $70 \%$ of cases respectively.

Recent prospective studies have also demonstrated an increased cardiovascular risk associated with MS, regardless of the presence of diabetes and irrespective of sex [7] [8]. The study by gender in our series showed no significant difference except for the hyper LDL cholesterol.

Association of MS with coronary heart disease in hemodialysis patients was demonstrated by several studies [9] [10], as well as association between MS and inflammation [2] [11] and between MS and secondary deaths to cardiovascular diseases [12] [13].

A study in patients on peritoneal dialysis with MS had found the increased risk of cardiovascular mortality, found in $40 \%$ of cases [14].

Another study showed that hemodialysis patients with MS have higher rates of hospitalization, but there was no significant difference in death from cardiovascular disease [15].

The increased risk of coronary artery disease can be explained by the pro thrombotic condition due to abdominal obesity and induced by high platelet activation and deregulated production of adipokines by adipose tissue. In fact, the MS is associated with platelet dysfunction, endothelial dysfunction and prothrombothique environment.

Table 1. Hemodialysis patients with MS: comparison by gender.

\begin{tabular}{cccc}
\hline Variable & M (N = 23) & $\mathbf{F ~ ( N = ~ 1 7 ) ~}$ & $\mathbf{p}$ \\
\hline Age (years) & 56.17 & 55.7 & 0.9 \\
Diabetes (\%) & 78.26 & 58.82 & 0.18 \\
Hypertension (\%) & 61.11 & 38.89 & 0.16 \\
Obesity (\%) & 51.85 & 48.14 & 0.18 \\
TG (mmol/l) & 3.82 & 2.57 & 0.1 \\
Hypo HDL (mmol/l) & 0.69 & 0.74 & 0.37 \\
Hyper LDL (mmol/l) & 2.66 & 3.84 & $\mathbf{0 . 0 3}$ \\
Coronaropathy & 60.9 & 52.9 & 0.16 \\
Heart failure & 56.5 & 47.1 & 0.74 \\
\hline
\end{tabular}

M: male, F: female. 
The concentration of CRP is due to the severity of MS and to cardiovascular risk [16]-[18]. High CRP was found in twenty-six (65\%) of our patients. A reverse epidemiology is found in MS with an opposite association between obesity and all-cause of mortality [19] [20]. Hypoalbuminemia in the MS is associated with increased cardiovascular disease and mortality risk [21] [22].

Recent studies have identified new factors associated with cardiovascular risk in the MS: Adiponectin and Leptin. Adiponectin negatively correlated with BMI and body fat percentage. It is reduced in patients with coronary artery disease. High leptin levels seems correlated with a higher risk of myocardial infarction, regardless of the level of obesity [23] [24].

The fatty acid binding protein (FABP4) is a group of molecules which coordinate intracellular responses. Recent studies show that the FABP4 rate is significantly correlated with body fat, blood pressure, insulin resistance and dyslipidemia in hemodialysis. The FABP4 is a new predictor of cardiovascular mortality in patients at high cardiovascular risk [25].

This study has some limitations due to its retrospective nature and small sample size. Other multicenter studies with comparative studies of hemodialysis patients with MS and without MS may provide more conclusive results.

\section{Conclusion}

MS is a pathological entity that provides a relatively large fraction of the population and exposes individuals to a higher risk of cardiovascular disease and/or type 2 diabetes. There is a high prevalence of cardiovascular complications in men but a significant difference by gender could not be demonstrated in our study. Further studies with a larger workforce could confirm this.

\section{Conflict of Interests}

The authors declare that there is no conflict of interests regarding the publication of this paper.

\section{References}

[1] Prasad, G.V. (2014) Metabolic Syndrome and Chronic Kidney Disease: Current Status and Future Directions. World Journal of Nephrology, 3, 210-219. http://dx.doi.org/10.5527/wjn.v3.i4.210

[2] Kubrusly, M., Oliveira, C.M., Simões, P.S., Lima, R.O., Galdino, P.N., Sousa, P.A., et al. (2015) Prevalence of Metabolic Syndrome According to NCEP-ATP III and IDF Criteria in Patients on Hemodialysis. Jornal Brasileiro de Nefrologia, 37, 72-78. http://dx.doi.org/10.5935/0101-2800.20150011

[3] Rasic-Milutinovic, Z., Perunicic, G., Pljesa, S., Gluvic, Z., Ilic, M. and Stokić, E. (2007) Metabolic Syndrome in HD Patients: Association with Body Composition, Nutritional Status, Inflammation and Serum Iron. Internal Medicine, 46, 945-951. http://dx.doi.org/10.2169/internalmedicine.46.0092

[4] Expert Panel on Detection, Evaluation, and Treatment of High Blood Cholesterol in Adults (2001) Executive Summary of the Third Report of the National Cholesterol Education Program (NCEP) Expert Panel on Detection, Evaluation, and Treatment of High Blood Cholesterol in Adults (AdultTreatment Panel III). JAMA, 285, 2486-2497. http://dx.doi.org/10.1001/jama.285.19.2486

[5] Hsu, C.Y., McCulloch, C.E., Iribarren, C., Darbinian, J. and Go, A.S. (2006) Body Mass Index and Risk for End-Stage Renal Disease. Annals of Internal Medicine, 144, 21-28. http://dx.doi.org/10.7326/0003-4819-144-1-200601030-00006

[6] Bakker, S.L., Gansevoort, R.T. and Zeeuw, D.D. (2007) Metabolic Syndrome: A Fata Morgana? Nephrology Dialysis Transplantation, 22, 15-20. http://dx.doi.org/10.1093/ndt/gfl581

[7] Isomaa, B., Almgren, P., Tuomi, T., Forsén, B., Lahti, K., Nissén, M., et al. (2001) Cardiovascular Morbidity and Mortality Associated with the Metabolic Syndrome. Diabetes Care, 24, 683-689. http://dx.doi.org/10.2337/diacare.24.4.683

[8] Lakka, H.M., Laaksonen, D.E., Lakka, T., Niskanen, L.K., Kumpusalo, E., Tuomilehto, J., et al. (2002) The Metabolic Syndrome and Total and Cardiovascular Disease Mortality in Middle-Aged Men. JAMA, 288, 2709-2716. http://dx.doi.org/10.1001/jama.288.21.2709

[9] Chen, H.H., Wu, C.J., Chen, Y.C., Tsai, C.S., Lin, F.J. and Yeh, H.I. (2006) Metabolic Syndrome Is Associated with Severe Coronary Artery Disease and Poor Cardiac Outcome in End-Stage Renal Disease Patients with Acute Coronary Syndrome. Coronary Artery Disease, 17, 593-596. http://dx.doi.org/10.1097/01.mca.0000224418.21563.6e

[10] Yang, S.Y., Chiang, C.K., Hsu, S.P., Peng, Y.S., Pai, M.F., Ho, T.I., et al. (2007) Metabolic Syndrome Predicts Hos- 
pitalization in Hemodialysis Patients: A Prospective Asian Cohort Study. Blood Purification, 25, 252-259. http://dx.doi.org/10.1159/000101698

[11] Shahrokh, S., Heydarian, P., Ahmadi, F., Saddadi, F. and Razeghi, E. (2012) Association of Inflammatory Biomarkers with Metabolic Syndrome in Hemodialysis Patients. Renal Failure, 34, 1109-1113. http://dx.doi.org/10.3109/0886022X.2012.713280

[12] Haffner, S.M., Valdez, R.A., Hazuda, H.P., Mitchell, B.D., Morales, P.A. and Stern, M.P. (1992) Prospective Analysis of the Insulin-Resistance Syndrome (Syndrome X). Diabetes, 41, 715-722. http://dx.doi.org/10.2337/diab.41.6.715

[13] Ford, E.S. (2005) Risks for All-Cause Mortality, Cardiovascular Disease, and Diabetes Associated with the Metabolic Syndrome: A Summary of the Evidence. Diabetes Care, 28, 1769-1778. http://dx.doi.org/10.2337/diacare.28.7.1769

[14] Park, J.T., Chang, T.I., Kim, D.K., Lee, J.E., Choi, H.Y., Kim, H.W., et al. (2010) Metabolic Syndrome Predicts Mortality in Non-Diabetic Patients on Continuous Ambulatory Peritoneal Dialysis. Nephrology Dialysis Transplantation, 25, 599-604. http://dx.doi.org/10.1093/ndt/gfp498

[15] Tu, S.F., Chou, Y.C., Sun, C.A., Hsueh, S.C. and Yang, T. (2012) The Prevalence of Metabolic Syndrome and Factors Associated with Quality of Dialysis among Hemodialysis Patients in Southern Taiwan. Global Journal of Health Science, 4, 53-62. http://dx.doi.org/10.5539/gjhs.v4n5p53

[16] Frohlich, M., Imhof, A., Berg, G., Hutchinson, W.L., Pepys, M.B., Boeing, H., et al. (2000) Association between C-Reactive Protein and Features of the Metabolic Syndrome: A Population-Based Study. Diabetes Care, 23, 18351839. http://dx.doi.org/10.2337/diacare.23.12.1835

[17] Jofre, R., Rodriguez-Benitez, P., Lopez-Gomez, J.M. and Pérez-Garcia, R. (2006) Inflammatory Syndrome in Patients on Hemodialysis. Journal of the American Society of Nephrology, 17, S274-S280. http://dx.doi.org/10.1681/asn.2006080926

[18] Ridker, P.M., Buring, J.E., Cook, N.R. and Rifai, N. (2003) C-Reactive Protein, the Metabolic Syndrome, and Risk of Incident Cardiovascular Events. Circulation, 107, 391-397. http://dx.doi.org/10.1161/01.CIR.0000055014.62083.05

[19] Kalantar-Zadeh, K., Block, G., Humphreys, M.H. and Kopple, J.D. (2003) Reverse Epidemiology of Cardiovascular Risk Factors in Maintenance Dialysis Patients. Kidney International, 63, 793-808. http://dx.doi.org/10.1046/j.1523-1755.2003.00803.x

[20] Al Saran, K., Elsayed, S., Sabry, A. and Hamada, M. (2011) Obesity and Metabolic Syndrome in Hemodialysis Patients: Single Center Experience. Saudi Journal of Kidney Diseases and Transplantation, 22, 1193-1198.

[21] Xie, Q., Zhang, A.H., Chen, S.Y., Lai, X., Zhang, F., He, L., et al. (2012) Metabolic Syndrome Is Associated with Better Nutritional Status, but Not with Cardiovascular Disease or All-Cause Mortality in Patients on Haemodialysis. Archives of Cardiovascular Diseases, 105, 211-217. http://dx.doi.org/10.1016/j.acvd.2012.01.012

[22] Stolic, R.V., Trajkovic, G.Z., Peric, V.M., Stolic, D.Z., Sovtic, S.R., Aleksandar, J.N., et al. (2010) Impact of Metabolic Syndrome and Malnutrition on Mortality in Chronic Hemodialysis Patients. Journal of Renal Nutrition, 20, 38-43. http://dx.doi.org/10.1053/j.jrn.2009.01.021

[23] Despres, J.P. and Lemieux, I. (2006) Abdominal Obesity and Metabolic Syndrome. Nature, 444, 881-887. http://dx.doi.org/10.1038/nature05488

[24] Tsai, J.P., Tsai, C.C., Liu, H.M., Lee, C.J., Liou, H.H. and Hsu, B.G. (2011) Hyperleptinaemia Positively Correlated with Metabolic Syndrome in Hemodialysis Patients. European Journal of Internal Medicine, 22, e105-e109. http://dx.doi.org/10.1016/j.ejim.2011.02.015

[25] Tsai, J.P., Liou, H.H., Liu, H.M., Lee, C., Lee, R. and Hsu, B.G. (2010) Fasting Serum Fatty Acid-Binding Protein 4 Level Positively Correlates with Metabolic Syndrome in Hemodialysis Patients. Archives of Medical Research, 41, 536-540. http://dx.doi.org/10.1016/j.arcmed.2010.09.007 